Revista de Ciencias Sociales - Número 67 (2015) - Páginas 49-65

Infancia de Rosa Luxemburg: Sobre las nociones de violencia, experiencia...

\title{
INFANCIA DE ROSA LUXEMBURG: SOBRE LAS NOCIONES DE VIOLENCIA, EXPERIENCIA E INFANCIA EN WALTER BENJAMIN
}

\author{
ROSA LUXEMBURG'S CHILDHOOD: \\ ON THE NOTIONS OF VIOLENCE, EXPERIENCE \\ AND CHILDHOOD IN WALTER BENJAMIN
}

\author{
AMANDA OLIVARES VALENCIA* \\ Universidad Diego Portales (Chile) \\ amanda.leonor.olival@gmail.com
}

\section{Resumen}

Una lectura del ensayo biográfico "Rosa Luxemburg 1871-1919” de Hannah Arendt, bajo el prisma del entramado conceptual planteado por Walter Benjamin en "Sobre una crítica de la violencia", "Sobre el concepto de historia”, entre otros textos. Con ello, se pretenden insinuar ciertas coincidencias entre el pensamiento de Benjamin y la lectura de Arendt de la biografía de Luxemburg, poniendo especial énfasis en las ideas de violencia mítica, violencia divina, derecho, experiencia, infancia, junto a otras nociones centrales planteadas por Benjamin.

* Abogada, Licenciada en Ciencias Jurídicas y Sociales, Universidad de Chile. Estudiante del Magíster en Pensamiento Contemporáneo: Filosofía y Pensamiento Político del Instituto de Humanidades de la Universidad Diego Portales. Dirección Postal: Avenida Santa María N 383, Departamento 31, Recoleta, Santiago de Chile. Artículo recibido el 23 de febrero de 2015 y aceptado el 25 de noviembre de 2015.

Revista de Ciencias Sociales - Número 67 (2015) - Universidad de Valparáíso - ISSN 0716-7725-Valparáiso, Chile 


\title{
Palabras clave
} Benjamin.

Violencia mítica, violencia divina, experiencia, infancia, Walter

\begin{abstract}
The paper develops a reading of the biographical essay "Rosa Luxemburg 1871-1919" by Hannah Arendt, through the scope of conceptual framework proposed by Walter Benjamin in a "Critique of Violence", "On the Concept of History", along with other texts. The objective is to imply some coincidence between the thought of Benjamin and the Arendt's reading of the biography of Luxemburg, with particular emphasis on the ideas of mythical violence, divine violence, law, experience, childhood, along with other central notions developed by Benjamin.
\end{abstract}

\section{Keywords} Benjamin.

Mythic violence; Divine violence; experience; childhood, Walter

\section{Introducción}

El presente ensayo se ocupa de encontrar cruces conceptuales en el pensamiento de Walter Benjamin y Hannah Arendt. Para ello, se propone una lectura del ensayo biográfico escrito por Arendt acerca de Rosa Luxemburg — titulado "Rosa Luxemburg 1871-1919”, que forma parte de la recopilación de ensayos de "Hombres en tiempo de oscuridad" de la autora, y originalmente fue publicado como una reseña al libro de Paul Nettl "Rosa Luxemburg” en el "The New York Review of Books" en 1966-, atendiendo a la caracterización que la autora hace del personaje y de sus acciones en el campo de la política, en particular lo que toca al grupo Espartaco. Esta lectura, a su vez, la ponemos en discusión con las conceptualizaciones benjaminianas acerca de la violencia, la infancia y la experiencia. La lectura nos permitirá comprender ciertos acercamientos entre Arendt y Benjamin que a primera vista son difíciles de ubicar. En principio uno podría estimar que ambos autores se distancian en su comprensión de la violencia, sin

Facultad de Derecho y Ciencias Sociales - Universidad de Valparaíso - Chile 
embargo en una lectura más profunda de ciertos textos de ambos autores podemos intuir que este distanciamiento no es tal.

\section{Acerca de las nociones de violencia y revolución en Benjamin y Arendt}

Podría ser interesante indagar en el desarrollo de las nociones de violencia y revolución en el pensamiento de Walter Benjamin y Hannah Arendt. Si leemos "Para una crítica de la violencia" de Walter Benjamin, nos daremos cuenta de que para el autor hay un vínculo entre la violencia y la revolución, y específicamente un vínculo entre lo que denomina violencia divina o violencia destructora de derecho, y la huelga general proletaria. En el texto, Benjamin enuncia lo que considera son los aspectos centrales que tendrían que ser atendidos para pensar la violencia de manera crítica, alejándose de las concepciones tradicionales asociadas a las escuelas del derecho natural y derecho positivo $^{2}$. En esa línea, desarrolla las nociones de violencia fundadora y violencia conservadora de derecho, como manifestaciones de lo que denomina violencia mítica, y que piensan la violencia en el marco de la distinción clásica entre medio y fines a que ambas escuelas del derecho hacen alusión. Benjamin explícitamente se quiere desmarcar de esta distinción, y propone una noción de violencia que, deshaciendo la distinción, se caracteriza a su vez por deshacer el derecho — destruirlo-; me refiero a lo que denomina violencia divina, no fundadora ni conservadora, sino por el contrario destructora del derecho. La huelga general proletaria es rechazada por el poder Estatal en tanto que

1. Benjamin, Walter: Estética y Política. Buenos Aires, Argentina: Las Cuarenta, 2009. (Trad. Tomás Joaquín Bartoletti y Julián Fava).

2. En alemán el título del ensayo es "ZurKritik der Gewalt"; una precisión necesaria para comprender la perspectiva inicial del texto, vinculada a la idea de violencia en relación con las escuelas del derecho natural y el derecho positivo, es que la palabra Gewalt en alemán remite también a la noción de poder instituido, poder legítimo, autoridad, fuerza pública. En ese sentido, ver: DERRIDA, Jacques: Fuerza de Ley. El "fundamento místico de la autoridad". Madrid, España: Tecnos, 2008. (Trad. Adolfo Barberá y Patricio Peñalver Gómez).

Revista de Ciencias Sociales - Número 67 (2015) - Universidad de Valparáíso - ISSN 0716-7725-Valparáiso, Chile 
manifestación de esta forma de violencia divina, entrando en pugna con la violencia conservadora del derecho, o el poder instituido.

Por otro lado, Hannah Arendt también traza un vínculo entre violencia y revolución. Tanto en "Sobre la revolución" 3 como en "Sobre la violencia" el fenómeno de la revolución es caracterizado como una forma del actuar humano propia del dominio público, es decir una acción de carácter político con una naturaleza lineal, sin un final predecible, una forma de intervención en el mundo que da inicio a un proceso imprevisible y definitorio de la forma de vivir en comunidad. La revolución, a su vez, aparece asociada a experiencias de violencia y de cambio, pero ambas experiencias vinculadas a la idea de provocar una liberación de la opresión que sea constitutiva de la libertad, donde el cambio se produce en el sentido de dar lugar a un nuevo origen, y la violencia aparece como instrumento para la constitución de una nueva forma de gobierno. Las nociones de Arendt asociadas a la revolución y a la violencia en principio quizá son asimilables a lo que Benjamin denomina formas de violencia mítica, entendidas en el marco de la distinción de medios y fines, y fundamentalmente como fundadora de derecho o de nuevas formas de organización de la comunidad; en ese sentido Arendt literalmente señala que "La 'violencia', como ya he dicho,

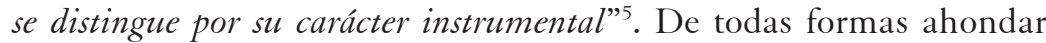
teóricamente en las distinciones, coincidencias y desavenencias planteadas por ambos autores en los textos antes citados no es el objetivo principal de este texto. Más bien en este ensayo queremos hacer ver las coincidencias y desavenencias que hay entre Benjamin y Arendt desde otra perspectiva.

Hannah Arendt en "Hombres en tiempos de oscuridad", se ocupa de abordar las figuras de algunas personas, la mayoría figuras

3. ARENDT, Hannah: Sobre la revolución. Madrid, España: Alianza Editorial, 2013. (Trad. Pedro Bravo).

4. ARENDT, Hannah: Sobre la violencia. Madrid, España: Alianza Editorial, 2013. (Trad. Guillermo Solana).

5. Ibíd., p. 62.

6. ARENDT, Hannah: Hombres en tiempos de oscuridad. Barcelona, España: Gedisa Editorial, 2001. (Trad. Claudia Ferrari y Agustín Serrano de Haro).

Facultad de Derecho y Ciencias Sociales - Universidad de Valparaíso - Chile 
destacadas del ámbito político, filosófico y literario de principios del siglo XX. En el prefacio de la compilación la autora señala que " $L a$ convicción que constituye el trasfondo inarticulado sobre el que estos retratos se dibujaron es que incluso en los tiempos más oscuros tenemos el derecho de esperar cierta iluminación, y que esta iluminación puede llegarnos menos de teorías y conceptos que de la luz incierta, titilante y a menudo débil que irradian algunos hombres y mujeres en sus vidas y obras (...)"' . El objetivo de este ensayo es, haciendo eco de lo señalado por Arendt, iluminar el sentido y el alcance de ciertas nociones utilizadas por Benjamin en ensayos como "Para un crítica de la violencia", "Sobre el concepto de historia", "El narrador", entre otros trabajos del autor, a partir de una figura trabajada en uno de los ensayos de Arendt en "Hombres en tiempos de oscuridad". En particular nos interesa la figura de Rosa Luxemburg, que como sujeto articulador nos puede ayudar a visualizar las nociones de revolución, violencia, experiencia, pobreza, infancia, relato, entre otras desarrolladas por Benjamin, poniéndolas en juego o también se podría decir "dinamizándolas” con el ensayo biográfico sobre Rosa Luxemburg de Arendt.

\section{Acerca de la violencia mítica y la violencia divina en la vida de Rosa}

Que Benjamin conocía la figura de Rosa no cabe duda, no está de más decir que Luxemburg es mencionada "al pasar" en una de las cartas que Benjamin dirige a Scholem (Carta de Benjamin a Scholem, Correspondencia $N^{\circ} 50,6$ de mayo de 1934$)^{8}$. Por otro lado, podríamos decir que el registro explícito más contundente que vincula a ambos personajes es la referencia al grupo "Espartaco" en la Tesis de filosofía de la historia XII del ensayo denominado "Sobre el concepto de historia", que a continuación cito textual: "El sujeto de conocimiento histórico es

7. Ibíd., p. 11.

8. Se trata de un referencia dada en el marco de una discusión a raíz de un comentario de Scholem plasmado en una carta anterior, donde le pregunta a Benjamin si acaso su artículo Zeitschriftfür Sozialforshcun se trata de un "credo comunista”. Ver: BENJAMIN, Walter, y Gershom Scholem: Correspondencia 19331940. Madrid, España: Trotta, 2011. (Trad. Rafael Lupiani), p. 116.

Revista de Ciencias Sociales - Número 67 (2015) - Universidad de Valparáíso - ISSN 0716-7725-Valparáiso, Chile 
la propia clase qué está oprimida y lucha. En la obra de Marx, aparece como la última clase sometida, como la clase vengadora, que, en nombre de las generaciones de vencidos, lleva hasta el final la obra de la liberación. Esta conciencia, que un breve tiempo volvió a tener vigencia con el grupo "Espartaco", siempre fue repulsiva para la socialdemocracia".

Como se puede leer, según Benjamin, el grupo Espartaco — del cual Rosa Luxemburg junto con Karl Liebknecht son identificados recurrentemente como sus líderes ${ }^{10}$ — tomó conciencia del rol de la clase oprimida en el camino para llevar a cabo la obra de la liberación en nombre de las generaciones de vencidos. Esta conciencia, que a su vez es repulsiva para la socialdemocracia, va a ser clave para entender el desenlace histórico y biográfico de Rosa Luxemburg, según lo relata Arendt.

Para Benjamin, la socialdemocracia ha sido conformista desde el principio, la teoría en la que se sostiene se basa en un concepto de progreso que no responde a la realidad, se vincula a la ilusión de que el trabajo de fábrica, que supuestamente conduciría al progreso tecnológico, constituye un logro político. La socialdemocracia se contentó con que la clase obrera haga el papel de redentora de las generaciones futuras ${ }^{11}$. El grupo Espartaco tomó conciencia de lo errada de esta comprensión, y de que en base a ella no se conseguiría la obra de la liberación, y por lo mismo pone la mirada en las generaciones pasadas. Rosa Luxemburg también es consciente del conformismo y la inmovilidad que afecta a la socialdemocracia, como se puede desprender de la frase que cito a continuación, a su vez citada e intervenida por Arendt en el ensayo en comento: "Una revolución es grande y fuerte siempre que los socialdemócratas [que en esa época seguía siendo el único partido revolucionario] no la aniquilen" ${ }^{12}$. Por lo demás Rosa es consciente

9. BENJAMIN, Walter: Conceptos de filosofía de la historia. Buenos Aires, Argentina: Terramar, 2007. (Trad. Héctor A. Murena y David Vogelmann), p. 150 .

10. ARENDT, Hannah: Hombres en tiempos de oscuridad. Ob. Cit. p. 44.

11. Ver Tesis de la filosofía de la historia XI, XII y XIII. En: Benjamin, Walter: Conceptos de filosofía de la historia .Ob. Cit.

12. ARENDT, Hannah: Hombres en tiempos de oscuridad. Ob. Cit. p. 62.

Facultad de Derecho y Ciencias Sociales - Universidad de Valparaíso - Chile 
de una cuestión que buena parte de sus coetáneo desconoce, que "las revoluciones no están hechas por nadie en especial sino que surgen en forma espontánea y que la urgencia de la acción siempre proviene de abajo"13.

Quizá sea difícil definir qué es aquello de lo que tomó conciencia el grupo Espartaco y que a ojos de Benjamin pone en vigencia el rol de las clases obreras en llevar hasta el final la obra de la revolución. Sin embargo, hay ciertos aspectos del relato histórico biográfico que desarrolla Arendt que pueden ayudarnos a iluminar la cuestión. La autora es muy enfática en señalar que los verdaderos errores en que incurrió Rosa durante su vida fueron "los pocos momentos cruciales en los que Rosa Luxemburg no estuvo en desacuerdo sino que pareció por el contrario estar conforme con el poder oficial del Partido Socialdemócrata Alemán"'14; Rosa militó activamente en el Partido Socialdemócrata Alemán, del que finalmente se desliga para conformar el grupo Espartaco, también denominado Liga Spartakus; sin embargo los desacuerdos con el Partido Socialdemócrata Alemán llegan hasta el punto que -luego de que el movimiento revolucionario alemán, denominado "Levantamiento de Spartakus" iniciado en enero de 1918, recibiera el apoyo de la liga ${ }^{15}$ — en enero de 1919 "Rosa Luxemburgo y Karl Liebknecht, los líderes de la Liga Spartakus, precursora del Partido Comunista alemán, fueron asesinados en Berlín bajo los ojos del régimen socialista que entonces estaba en el poder (...)"'16; con ello, sumado a una serie de otros antecedentes, "la división de la izquierda europea en los Partidos Socialista y Comunista llegó a ser irrevocable (...)”"17, a sabiendas

13. Ibíd.

14. Ibíd., p. 57.

15. Arendt es consciente de que la Liga Spartakus "seguía los sucesos más que crearlos" y nos señala que "la noción oficial de que el Levantamiento de Spartakus en enero de 1918 fuera causado e inspirado por sus líderes — Rosa Luxemburg, Liebknecht, Jogiches— es un mito”. Ver: ARENDT, Hannah: Hombres en tiempos de oscuridad. Ob. Cit. p. 56.
16. Ibíd., p. 45.
17. Ibíd., p. 46.

Revista de Ciencias Sociales - Número 67 (2015) - Universidad de Valparáíso - ISSN 0716-7725-Valparáiso, Chile 
de que el asesinato fue cometido con la ayuda del gobierno e inducido por el mismo. Con ello no quiero insinuar que la división en la izquierda se debió al asesinato de Luxemburgo y Liebknecht, si no que más bien, fue este el hecho el que provocó que las diferencias fueran insuperables.

Aparentemente aquella conciencia que la Liga Spartakus puso en vigencia era de tal peligrosa magnitud, de tal amenazante envergadura para la Socialdemocracia — entonces en el poder-, que a ojos del poder instituido ameritaba medidas tales como el asesinato. En ese sentido, es pertinente citar a Benjamin, quien nos dice “(...) en el ejercicio de la violencia sobre vida y muerte el derecho se refuerza a sí mismo, más que en cualquiera otra ejecución jurídica (Rechtsvollzug)"'18. Parece que aquella conciencia que Benjamin reconoce en la liga Spartakus amenazaba el poder instituido de tal manera, que era necesario reafirmarlo con mayor ejercicio de violencia reforzador del poder.

Pero quizá lo más elocuente de esta historia dice relación con lo que desarrolla Arendt respecto a la legalidad de los asesinatos: "el asesinato de Liebknecht y Luxemburg fue totalmente legal, 'una ejecución de acuerdo con la ley marcial'”, es más, el "soldado Runge (que había golpeado a Rosa Luxemburg en la cabeza en los corredores del Hotel Eden)" fue castigado "con una pena de prisión de dos años y dos semanas por 'intento de asesinato'”, y el "teniente Vogel (el oficial a cargo cuando Rosa recibió un tiro en la cabeza dentro del coche y fuera arrojada al canal Landwehr) con una pena de cuatro meses por "no haber informado sobre el cadáver y disponer ilegalmente de este" ${ }^{\prime 1}$. Ninguna de las condenas impuestas a los ejecutores de los asesinatos de Luxemburgo y Liebknecht se debió a la consideración de que sus acciones eran ilegales o reprochables legalmente, sino por el contrario, se deben a defectos en la ejecución de una acción que el ordenamiento jurídico considera completamente legítima.

Queda claro que el derecho ampara la violencia puesta en práctica en el asesinato de Liebknecht y Luxemburg; se trata de un caso de

18. BENJAMIN, Walter: Estética y Política. Ob. Cit. p. 44.

19. ARENDT, Hannah: Hombres en tiempos de oscuridad. Ob. Cit. p. 45.

Facultad de Derecho y Ciencias Sociales - Universidad de Valparaíso - Chile 
violencia legal, o lo que Benjamin también llama "violencia conforme a destino". El ordenamiento jurídico positivo establece un orden, y la violencia amenaza para la conservación de este ordenamiento. Sin embargo también "el derecho observa que la violencia a disposición de individuos es un peligro capaz de socavar el ordenamiento jurídico" 20 cuando esta existe fuera del derecho.

Para dar mayor luz a los hechos relatados es útil recurrir al apartado de "Para una crítica de la violencia" en que Benjamin se ocupa de revisar el caso donde la manifestación de la violencia todavía está permitida por el derecho; se trata del caso del derecho a huelga de los trabajadores en relación con la huelga general proletaria. Según Benjamin aparentemente en ambos casos se hace ejercicio de un mismo derecho, sin embargo en el primero el ejercicio del derecho es indiferente para el ordenamiento jurídico, en cambio en el segundo es hostil, y empieza a ser denominado violencia — pues justamente es cuando se trata del ejercicio de un derecho para subvertir el ordenamiento jurídico. Benjamin señala que “(...) en la huelga el Estado teme, más a que cualquier otra función de la violencia, a aquella que se indaga como el único fundamento seguro de su crítica. (...) la huelga muestra que sí es capaz de fundar y modificar relaciones de derecho, aun cuando el sentimiento de justicia se considere ofendido por ella" 21 , y más delante agrega: "El estado le teme, más que a cualquier otra cosa, a que esta violencia funde derecho en el mismo grado en que él debe fundarlo"22. En definitiva, el Estado le tema a aquella forma de violencia que es capaz de destruirlo, y que eventualmente podría implicar la nueva fundación de un orden en el lugar que ocupaba el Estado.

La violencia legal se identifica con lo que Benjamin denomina violencia mítica; entonces el autor se plantea la pregunta por una violencia inmediata pura, que pudiese poner término a la violencia mítica, lugar donde aparece la violencia divina, que a diferencia de la

\footnotetext{
20. BENJAMIN, Walter: Estética y Política. Ob. Cit. p. 38.

21. Ibíd., p. 41

22. Ibíd., p. 42.
}

Revista de Ciencias Sociales - Número 67 (2015) - Universidad de Valparáíso - ISSN 0716-7725-Valparáiso, Chile 
mítica, es destructora de derecho. "Si la violencia mítica funda derecho, la violencia divina lo destruye (rechtsvernichtend). Si la primera establece límites, la segunda los destruye de forma ilimitada. Si la violencia mítica culpa (verschuldend) y expía (sühnend) al mismo tiempo, la divina solo absuelve (entsühnend). Si una amenaza, la otra golpea. Si aquella es sangrienta, esta segunda es letal sin derramar sangre"23. Se trata de una forma de violencia irreconocible e improducible por un grupo o una persona, pues nunca es medio, sino que es pura y reinante.

No está demás reiterar que, según Arendt, uno de los aspecto de los que Rosa era consciente es de que las revoluciones no están hechas por nadie, sino que surgen de manera espontánea, y su urgencia proviene desde abajo. Es decir, para Arendt una revolución es improducible, como también es incontrolable para un grupo de personas, es inmanipulable, tiene fuerza propia y se dirige conforme a sus propias inclinaciones. Rosa Luxemburg era consciente de ello, y lo fue también cuando la Liga Spartakus prestó apoyo al movimiento revolucionario alemán "Levantamiento de Spartakus".

Quizá es demasiado osado decir que el derecho, el poder instituido, al poner en práctica la violencia legal máxima en contra de Liebknecht y Luxemburg, lo que hizo fue protegerse de una manifestación de la violencia pura, destructora, a la que nos referimos como violencia divina, "pues solo la violencia mítica, no la divina, se dejará reconocer con certeza como tal”24. Una de las características de la violencia divina, sin duda, es su irreconocibilidad a ojos de los seres humanos. Por lo mismo, difícilmente podemos decir que el Levantamiento Spartakus, apoyado por la Liga, era una manifestación de violencia divina. Sin embargo pareciera ser que el Estado vio en ella una amenaza a su estabilidad tal, que decidió reforzarse a sí mismo mediante un ejercicio de violencia sobre la vida, en particular sobre la de Liebknecht y Luxemburg. Dejo esbozada la duda, pero de todas formas el entramado conceptual de Benjamin queda planteado.

\footnotetext{
23. Ibíd., p. 58.

24. Ibíd., p. 62.
}

Facultad de Derecho y Ciencias Sociales - Universidad de Valparaíso - Chile 


\section{Acerca de las nociones de infancia, juventud y narración en Benjamin y Arendt}

Para empezar a concluir este trabajo, hay ciertos aspectos levantados por Arendt respecto a la figura de Rosa Luxemburg que estimo sería interesante comentar. En primer lugar llama la atención que la figura de Luxemburg aparezca vinculada a un entusiasmo juvenil de los movimientos de izquierda: "Cada movimiento de la Nueva Izquierda, cuando llegaba el momento de cambiar y convertirse en Vieja Izquierda (...) enterraba su temprano entusiasmo por Rosa Luxemburg junto con sus sueños de juventud; (...) les resultaba fácil prescindir de ella con todo el aire filisteo que animaba su nuevo estatuto adquirido. El 'luxemburguismo' (...) se lo trataba tan sólo como una enfermedad inocua e infantil"25. Veremos que en Benjamin también está presente una cierta oposición entre la figura del joven, quien entiende la vida a través de ciertos valores que exceden la mera experiencia, vinculado a la noción de sentido y de espíritu, y la figura del filisteo, quien aparentemente reduce su comprensión del mundo a un mínimo acotado y falto de sentido.

Por otro lado, también llama la atención que Arendt destaque como parte fundamental del contexto íntimo de Rosa Luxemburg el "grupo de camaradas" polaco-judío, de donde aparentemente Rosa extrae su formación valorativa: "el secreto denominador común de aquellos que siempre se trataron como iguales (y a casi nadie más) era la simple experiencia de un mundo infantil donde el respeto mutuo y la confianza incondicional, una humanidad universal y un desprecio genuino, casi ingenuo, por las distinciones sociales y étnicas, se daba por sentado. Aquello que el grupo de camaradas tenía en común era algo que solo puede llamarse gusto moral, que es muy diferente de los 'principios morales'; (...) Este ambiente, y nunca el partido alemán, fue y siguió siendo el hogar de Rosa Luxemburg"26. De este fragmento uno puede leer una tesis subyacente, según la cual, el aprendizaje que definió la configuración valorativa de

\footnotetext{
25. ARENDT, Hannah: Hombres en tiempos de oscuridad. Ob. Cit. p. 48.

26. Ibíd., p. 51.
}

Revista de Ciencias Sociales - Número 67 (2015) - Universidad de Valparáiso - ISSN 0716-7725-Valparáís, Chile 
Rosa Luxemburg se produce durante su niñez, en la experiencia de compartir con un grupo de iguales, y muy posiblemente por la transmisión de cierta sabiduría de parte del grupo de adultos, la familia, a los más jóvenes. Como bien lo destaca Arendt: "Nettl señala acertadamente la excelente relación de Rosa Luxemburg con su familia, sus padres, sus hermanos, su hermana, su sobrino" ${ }^{27}$. Esta idea, de la transmisión de una cierta sabiduría de los mayores a los jóvenes, también aparece planteada en Benjamin, a través de la idea de la experiencia.

Aparentemente, para Arendt habría algo de lo infantil y de lo juvenil que se hace parte en la figura de Luxemburg de manera eminente, definiendo su formación valórica y vinculando su figura a sueños de juventud. Se podría trazar un vínculo entre esta imagen arendtiana de Rosa Luxemburg, y algunos pasajes de textos tempranos y tardíos de Benjamin, relacionados a la idea de experiencia, pobreza y juventud, entre otros.

Partamos haciendo referencia a una figura a la que tanto Arendt como Benjamin aluden, el filisteo. En un texto temprano de Benjamin titulado "Experiencia" (1913), se desarrolla la idea de la experiencia como una máscara del adulto que encubre la falta de sentido de la vida, la brutalidad, asociándolo a la figura del filisteo ${ }^{28}$, se señala: "El filisteo no comprende que existe algo más que la experiencia, que hay valores (inexperimentables) a cuyo servicio nosotros estamos" ${ }^{29}$. Sin embargo, no es que para Benjamin la experiencia carezca de sentido por sí misma,

\section{Ibíd., p. 51.}

28. Una nota de la traducción al español del texto "Diálogo sobre la religión del presente" puede ser esclarecedora, se señala: "La palabra alemana Philister era utilizada desde finales del siglo XVIII por los estudiantes de universidad para referirse despectivamente a las personas de la generación de sus padres que, gozando de una situación económica acomodada, carecían de gusto artístico y literario y no se recataban en exhibir públicamente su mal gusto. Ver Nota 2, de Diálogos sobre la religiosidad del presente. En: Benjamin, Walter: Obras. Libro II, Volumen 1. Primeros trabajos de crítica de la educación y de la cultura; estudios metafísicos y de filosofía de la historia; ensayos estéticos y literarios. Madrid, España: Abada Editores, 2007. (trad. Jorge Navarro Pérez).

29. BENJAMIN, Walter: Obras. Libro II, Volumen 1. Ob. Cit. p. 55.

Facultad de Derecho y Ciencias Sociales - Universidad de Valparaíso - Chile 
sino sólo cuando está abandonada por el espíritu, como es en el caso del filisteo, quién hace suya la eterna experiencia de la carencia de espíritu; el joven en cambio quiere experimentar el espíritu. Es esa experiencia la que persigue cada movimiento de la Nueva Izquierda, según indica Arendt, viendo en la figura de Rosa una manifestación de aquel espíritu que buscan abrazar.

En otro sentido en "Experiencia y Pobreza" (1933), Benjamin reflexiona a partir de una fábula de Esopo - "El labrador y sus hijos"donde un anciano comunica una experiencia a sus hijos, y a partir de ello desarrolla una idea de la pérdida de la experiencia (o su pobreza), donde esta es representada por el autor como aquello que los adultos dan a los jóvenes, pero ya no en un sentido negativo - experiencia sin espíritu-, sino que en el sentido de una dimensión de la vida perdida y que es añorada por el autor. La pérdida de la experiencia es enunciada por Benjamin a través de una serie de preguntas "¿Qué fue de todo eso? ¿Dónde podemos encontrar a alguien que sepa aún relatar bien algo? (...) ¿Y quién intentará despachar a la juventud apelando así a su experiencia?”30, preguntas que son retomadas en otros textos del autor “¿Por qué se está acabando el arte de contar historias?" 31.

Para Benjamin la facultad de intercambiar experiencia se vincula directamente con la narración, con el arte de contar relatos: "El narrador toma lo que narra de la experiencia; [de] la suya propia o la referida. Y la convierte a su vez en experiencia de aquellos que escuchan su historia" ${ }^{\prime 32}$; y así como la cotización de la experiencia ha caído, se ha acabado el arte de contar historias. Tras la Primera Guerra Mundial comenzó a hacerse evidente un proceso que desde entonces no ha llegado a detenerse "¿No se advirtió que la gente volvía enmudecida del campo de batalla? No más rica, sino más pobre en experiencia comunicable" ${ }^{\prime 3}$. Este proceso decanta

30. Ibíd., p. 217.

31. BENJAMIN, Walter: Historias desde la soledad y otras narraciones. Buenos Aires, Argentina: El cuenco de plata, 2013. (Trad. Ariel Magnus). P. 95.

32. BENJAMIN, Walter. El Narrador. Santiago, Chile: Ediciones Metales Pesados, 2010. (Trad. Pablo Oyarzún Robles). P. 65.

33. Ibíd., p. 60.

Revista de Ciencias Sociales - Número 67 (2015) - Universidad de Valparáíso - ISSN 0716-7725-Valparáiso, Chile 
en la idea de una pérdida de la sabiduría: “(...) la sabiduría suele manifestarse como narración. Por eso el contador de historias es también alguien que sabe dar consejo. Y para recibirlo, uno mismo debe contarle cosas a él" ${ }^{\prime 34}$. Benjamin ve en el acabamiento del arte de contar historias un síntoma de la época, consecuencia de la guerra, y que puede tener por efecto que generaciones jóvenes no reciban de sus mayores aquella sabiduría que era transmitida a través del relato.

Quizá nos encontramos antes un aspecto un tanto indescifrable de la obra de Benjamin, pero me parece que hay ciertas cuestiones que son difíciles de ignorar. El vínculo entre aquello que Benjamin llama experiencia y la juventud, la experiencia carente de espíritu como un sin sentido, evocado en la figura del filisteo, y por oposición, la experiencia del espíritu, propia de la infancia y la juventud, y profundamente degradada luego de la Guerra, cuyo empobrecimiento se refleja en la pérdida del arte de contar historias.

En todo caso, Hannah Arendt no parece ignorar el valor que detenta el relato. Por el contrario, consiente de la sabiduría subyacente en él, hace el esfuerzo de escribir esta serie de ensayos reunidos bajo el título de "Hombres en tiempo de oscuridad", abordando la vida de personajes de la historia cuya experiencia personal fue atravesada por la guerra. Pareciera como si Arendt quisiera responder al diagnóstico de Benjamin respecto al enmudecimiento de la gente a la vuelta del campo de batalla tras la Primera Guerra Mundial, y por lo mismo, constatado ese enmudecimiento, ahora extendido a toda la primera mitad del siglo XX, la autora decide buscar algunas experiencias de la época que nos permitan iluminar y aconsejar la vida en los años postreros: que “(...) incluso en los tiempos más oscuros tenemos el derecho de esperar cierta iluminación, y que esta iluminación puede llegarnos menos de teorías y conceptos que de la luz incierta, titilante y a menudo débil que irradian algunos hombres y mujeres en sus vidas y obras (...)"35. Sin duda Arendt ve sabiduría en la experiencia vívida de ciertos personajes, que se puede dar a conocer a través de estos relatos.

\footnotetext{
34. BENJAMIN, Walter: Historias desde la soledad y otras narraciones. Ob. Cit. p. 96.

35. Ibíd., p. 11.
}

Facultad de Derecho y Ciencias Sociales - Universidad de Valparaíso - Chile 
Quizá en Rosa Luxemburg encontramos aquella experiencia plena de sentido, comunicable a través del relato, y asociada al espíritu de la juventud. Arendt se hace cargo de contarla. Así como también se hace cargo de contar al menos una parte de la experiencia de vida de Benjamin, en otro de los ensayos publicados en el mismo libro.

Para concluir quisiera hace referencia a la siguiente cita, que refleja aquella relación entre la niñez, la experiencia del espíritu, y aquella fuerza liberadora que se opone a lo mítico, y que quizá fue puesta en vigencia por Luxemburg a través de aquella toma de conciencia a la que Benjamin hace referencia en la Tesis de la filosofía de la historia XII, tal como antes se comentó: "lo más aconsejable, así le ha enseñado el cuento desde antaño a la humanidad, y sigue haciéndolo hoy a los niños, es oponerse a las fuerzas del mundo mítico con astucia e insolencia. (...) La magia liberadora de que dispone el cuento, no pone en juego a la naturaleza de modo mítico, sino que es la alusión a su complicidad en el hombre liberado. Esta complicidad la experimente el hombre maduro sólo esporádicamente, en la dicha; pero al niño se le aparece por vez primera en el cuento y lo hace dichoso"36. Hay una magia liberadora en el cuento, en el relato, que enseña a los niños como oponerse a las fuerzas míticas, y que el adulto solo aparece a ratos. Podría ser que aquello que ven los movimiento de la Nueva Izquierda en la figura de Rosa tenga relación con el relato que en torno al personaje se ha construido, que hace constante eco a la obra de la liberación, como se indicaba en la Tesis de filosofía de la historia XII, y que como también vimos en el apartado anterior, evoca manifestaciones de violencia divina.

Por lo mismo, tal vez, tanto para Arendt como para Benjamin, la percepción del luxemburguismo como una enfermedad inocua e infantil, y la explicación de su formación valórica en la simple experiencia de un mundo infantil compartido para el grupo de camaradas, no tiene nada de casual. Sin duda de ello quiere dar cuenta Arendt en este ensayo que hemos comentado.

\section{Conclusiones}

Este ensayo buscó mostrar ciertos acercamientos entre el pensamiento de Arendt y Benjamin a través de una lectura del ensayo

36. Ibíd., p. 87.

Revista de Ciencias Sociales - Número 67 (2015) - Universidad de Valparáíso - ISSN 0716-7725-Valparaíso, Chile 
biográfico acerca de Rosa Luxemburg publicado en el libro "Hombres en tiempos de oscuridad", escrito por Hannah Arendt.

Respecto a las conceptualizaciones relativas a la violencia y la revolución en ambos autores, hemos visto cómo es posible visualizar en el relato de Arendt respeto de Luxemburg, ciertos rasgos de lo que en el entramado conceptual de Benjamin se denomina violencia divina, sobre todo en análisis de la respuesta estatal a las acciones políticas de Luxemburg, en el marco del accionar del grupo Espartaco.

Respecto a las nociones de experiencia, juventud y relato, hemos visto como Arendt pone particular énfasis en las experiencias de niñez como origen de la formación valorativa de Luxemburg. Así como también que la figura de Rosa aparece asociada a ideales de juventud de grupos políticos de izquierda, luego abandonados cuando estos encuentran su propia madurez. Ambas ideas nos resuenan en Benjamin a través de las nociones de experiencia y juventud, y en la figura del filisteo, que Arendt también saca a relucir en su ensayo.

Por último, Arendt al abocarse a retratar y relatar la vida personajes relevantes en la primera mitad del siglo XX, hace un esfuerzo por buscar iluminar cierta oscuridad que se puede ver también mencionada por Benjamin en su diagnóstico respecto al empobrecimiento de la experiencia después de la Primera Guerra. En esa línea, vemos en el esfuerzo narrativo de Arendt una respuesta a este diagnóstico, buscando preservar parte de aquella experiencia que se ha perdido por lo que Benjamin llama el enmudecimiento de la gente después del campo de batalla.

Con todos estos aspectos nos parece que hemos mostrado algunos acercamientos en el pensamiento de ambos autores, además de plantear un análisis conceptual respecto de la figura de Rosa Luxemburg,

\section{REFERENCIAS BIBLIOGRÁFICAS}

ARENDT, Hannah: Hombres en tiempos de oscuridad. Barcelona, España: Gedisa Editorial, 2001. (Trad. Claudia Ferrari y Agustín Serrano de Haro).

ARENDT, Hannah: Sobre la revolución. Madrid, España: Alianza Editorial, 2013. (Trad. Pedro Bravo).

Facultad de Derecho y Ciencias Sociales - Universidad de Valparaíso - Chile 
ARENDT, Hannah: Sobre la violencia. Madrid, España: Alianza Editorial, 2013. (Trad. Guillermo Solana).

BENJAMIN, Walter: Conceptos de filosofía de la historia. Buenos Aires, Argentina: Terramar, 2007. (Trad. Héctor A. Murena y David Vogelmann).

BENJAMIN, Walter: Obras. Libro II, Volumen 1. Primeros trabajos de crítica de la educación y de la cultura; estudios metáfisicos y de

filosofía de la historia; ensayos estéticos y literarios. Madrid, España: Abada Editores, 2007. (Trad. Jorge Navarro Pérez).

BENJAMIN, Walter: Estética y Política. Buenos Aires, Argentina: Las Cuarenta, 2009. (Trad. Tomás Joaquín Bartoletti y Julián Fava).

BENJAMIN, Walter. El Narrador. Santiago, Chile: Ediciones Metales Pesados, 2010. (Trad. Pablo Oyarzún Robles).

BENJAMIN, Walter: Historias desde la soledad y otras narraciones. Buenos Aires, Argentina: El cuenco de plata, 2013. (Trad. Ariel Magnus).

BENJAMIN, Walter, y Gershom Scholem: Correspondencia 1933-1940. Madrid, España: Trotta, 2011. (Trad. Rafael Lupiani).

DERRIDA, Jacques: Fuerza de Ley. El "fundamento místico de la autoridad”. Madrid, España: Tecnos, 2008. (Trad. Adolfo Barberá y Patricio Peñalver Gómez). 